\title{
El SENTIDo INTERNo, TópICA NATURAL DE LA INVENCIÓN EN A. G. BAUMGARTEN
}

\author{
Maximiliano Hernández Marcos
}

(Universidad de Salamanca)

\section{Idea de una Tópica Natural del Sujeto Estético}

La Aesthetica (1750-1758) de A. G. Baumgarten representa el intento de elaborar una nueva Tópica de la invención específicamente artística, capaz de suministrar el conocimiento de lo individual que no podía proporcionar la Tópica lógico-retórica tradicional, atrapada en la vacuidad genérica y superflua de sus loci universales ${ }^{1}$. Su propósito último y su tarea consiste en establecer los criterios estéticos de racionalidad de lo sensible a modo de loci particulares que orienten y regulen la creación de una obra de arte bella en general. Las seis categorías de perfección del conocimiento sensible enumeradas en el $\$ 22$ de la Aesthetica (ubertas, magnitudo, veritas, claritas, certitudo y vita), en torno a las cuales se articula el amplio e inacabado capítulo de la "Heurística", son invocadas a este respecto en el $\$ 139$ como los nuevos lugares argumenta-

\footnotetext{
${ }^{1}$ Sobre esta interpretación v. M. Hernández Marcos, “A la búsqueda de un criterio estético de la razón. La Aesthetica de A. G. Baumgarten como Tópica moderna de la invención", Biblos (Coimbra), 2 (2014), 319-349. El presente artículo es continuación del tema allí abordado. La visión de Baumgarten sobre la Tópica está expuesta en su Aesthetica, cap. I, sect. X (\$\$130-141) y en los parágrafos correspondientes de su Kollegium über Ästhetik. De ambos textos se manejan aquí las siguientes ediciones: la reciente edición bilingüe de Dagmar Mirbach $\ddot{A}$ sthetik, Lateinisch-Deutsch, Hamburg: Felix Meiner, 2007, 2 vols. [= Ästhetik] [se ha consultado también y es recomendable la edición italiana de Salvatore Tedesco L'Estetica, Palermo: Aesthetica Edizioni, 2000]; y la edición del Curso de Estética a cargo de Bernhard Poppe A. G. Baumgarten: seine Bedeutung und seine Stellung in der Leibniz-Wolffischen Philosophie und seine Beziehungen zu Kant. Nebst Veröffentlichung einer bisher unbekannten Handschrift der Ästhetik Baumgartens, Bern/Leipzig: R. Noske, 1907 [= Kollegium].
}

Philosophica, 44, Lisboa, 2014, pp. 65-91. 
tivos de una "Tópica particular" de la invención artística, como los genuinos topoi aesthetici ${ }^{2}$. La idea inicial de la Estética como un ars inveniendi que enseña las reglas para la producción de una obra (Sección I, $\S 18$ y ss.), se resuelve así, a partir de la Sección VIII, en la elaboración de una Tópica "objetiva", de una teoría de los argumentos y de las figuras de belleza en los que se despliegan y concretan artísticamente aquellos criterios de perfección sensible. Y en la medida en que ella es la doctrina o saber racional acerca de las reglas de un arte -el de la creación estética-, constituye asimismo una Topica artificialis, es decir, representa el desarrollo efectivo de la nueva ciencia del pulcre cogitare fundada por Baumgarten, a la cual, en virtud de su estatuto propiamente epistémico de teoría del arte bello, él califica de Aesthetica artificialis o también de disciplina aesthetica ${ }^{3}$.

En el §140, el penúltimo de la Sección X, dedicada a la "Tópica", Baumgarten lleva a cabo, sin embargo, un giro que sorprende en principio. Allí se propone una Tópica estética alternativa, basada en el "catálogo completo de las facultades sensibles del alma" y en su desarrollo adecuado en la figura concreta o "carácter" de un felix aestheticus, es decir, de un individuo con una dotación armónica y afortunada de las capacidades naturales de su sensibilidad y con una formación apropiada de ellas ${ }^{4}$. La idea de una Tópica artificial y objetiva de la invención artística, encargada de dar a conocer las reglas de belleza derivables de los seis criterios gnoseológicos de perfección sensible, cede de esta manera su sitio a una Tópica natural y subjetiva, cuyo hilo conductor es tanto la "Psicología empírica", elaborada e incluida por el propio Baumgarten en su Metaphysica, como, sobre todo, su aplicación especial a la definición del sujeto estético en la parte de la Aesthetica dedicada al "esteta innato" o "espíritu bello" y de "buen corazón" (Sección II) ${ }^{5}$. A semejante prima-

${ }^{2}$ Ästhetik, §139. Cf. Kollegium, §139, p. 140. Sobre el catálogo de las seis categorías de lo bello como Tópica estética sustitutiva del arte tópico tradicional véase también G. F. Meier, Anfangsgründe aller schönen Wissenschaften, Halle/Magdeburg: C. H. Hemmerde, 1748-1750, §212, pp. 504-505. [=Anfangsgründe]

${ }^{3}$ La Estética como teoría sobre las reglas de la creación artística constituye un ars o disciplina aesthetica (cf. Ästhetik, §68; cf. §62; Kollegium, §68 y §70, pp. 110-111; cf. §62, pp. 106-107), y merece por ello la denominación de Aesthetica artificialis (cf. Ästhetik, §2; Kollegium, §2, p. 72). Cf. G. F. Meier, Anfangsgründe, §12, pp. 17-18.

${ }^{4}$ Ästhetik, §140; cf. Kollegium, §140, p. 140.

${ }^{5}$ Conviene recordar que el sujeto estético o artista genuino (felix aestheticus) es para Baumgarten algo más complejo que un simple individuo de talento natural, provisto de una proporción adecuada de facultades psíquicas (ingenium venustum et elegans connatum y temperamentum aestheticum connatum); constituye más bien un sujeto de talento o sensibilidad bien formada y desarrollada mediante el ejercicio de sus disposiciones innatas (exercitatio) y el conocimiento del mundo y de las reglas del 
cía de la Tópica psicológica del sujeto creador sobre la Tópica preceptiva de las reglas de perfección sensible en el proceso de invención artística parece contribuir el propio orden expositivo de las materias adoptado por Baumgarten en su Aesthetica, al anteponer el tratamiento de la "Estética natural" del buen artista al de la "Estética artificial" de los argumentos y figuras de belleza, en clara desautorización del orden inverso seguido por su discípulo G. F. Meier en sus Anfangsgründe aller schönen Wissenschaften (1748-1750). Se trata -arguye Baumgarten- de atenerse al "orden más natural" de la cosa, el cual requiere, antes de determinar qué es lo estéticamente bello de una obra de arte, saber "cómo ha de estar constituido el sujeto que ha de producirla", ya que el "efecto" no puede ser en modo alguno "más grande ni más noble que su causa próxima", y, por tanto, la calidad del objeto artístico tiene que depender a este respecto de la "potencia viva" de su alma creadora 6 .

Conviene reparar en este argumento de Baumgarten, porque explicita el motivo por el cual el filósofo de Frankfurt am Oder se plantea construir su Estética según la idea de una tópica psicológica del sujeto creador. Ese motivo es que las reglas inventivas de lo bello no se hallan en las grandes producciones artísticas sino en la medida en que están ya inscritas en la naturaleza del alma humana, de manera que no hay, en rigor, buenas obras de arte sino buenos artistas, ni cabe formular precepto alguno sobre la belleza y su creación más que extrayéndolo por reflexión abstracta a partir del arsenal depositado en un "espíritu bello" y de "buen

arte (disciplina aesthetica), y que cuenta además con una capacidad de inspiración (impetu aestheticus) y un hábito reflexivo de corrección de sus obras (correctio aesthetica). El componente psicológico del buen artista se reduce, pues, a aquella base estrictamente innata del talento creador ("Estética natural innata" - ̈̈sthetik, $\S 28$ ), que consta a su vez de una determinada disposición cognoscitiva (un "espíritu bello y elegante" - Ästhetik, §§29 ss.) y de un determinado temperamento o inclinación apetitiva (un "buen corazón" o voluntad para lo grande - Ästhetik, §§44 ss.). A esta peculiar dotación psicológica de facultades sensibles que define la fuerza creadora de un buen artista, su talento innato, es a lo que Baumgarten llama, en sentido estricto, "Estética natural", de la cual se ocupa en la Sección II de su Aesthetica, y que constituye, en realidad, una aplicación o derivación de la "Psicología empírica" expuesta en la Metaphysica (1739) (cf. Ursula Franke, Kunst als Erkenntnis. Die Rolle der Sinnlichkeit in der Ästhetik des Alexander Gottlieb Baumgartens, Wiesbaden: Franz Steiner, 1972, p. 83).

${ }^{6}$ Cf. respectivamente Kollegium, §27, p. 85, y Ästhetik, §27. El mismo argumento figura en G. F. Meier, Anfangsgründe, \$3, p. 6; $\$ 10$, p. 15, quien, sin establecer ninguna prelación al respecto, aborda, no obstante, las "dos fuentes" principales de reglas estéticas empezando la exposición por la fuente objetivo-preceptiva ("las reglas de las perfecciones y bellezas en general"), y continuando por la subjetivo-psicológica ("la doctrina del alma y especialmente de su facultad cognoscitiva inferior"). 
corazón", en las capacidades psíquicas innatas de un talento creador ${ }^{7}$. Tal como Meier explicara con toda contundencia, sin un alma dotada naturalmente para "las ideas bellas" resulta vano todo esfuerzo creativo; el arte, para ser auténtico, "debe seguir a la naturaleza".

Esta dependencia de la práctica artística con respecto al sujeto creador alcanza también a la Estética misma como teoría sobre las reglas de la invención y representación artísticas. La nueva disciplina filosófica debe, en efecto, a la existencia de tales mentes de naturaleza creadora tanto su sentido corrector o educativo, en cuanto conocimiento racional, claro y distinto, como su posibilidad epistémica, en cuanto ciencia acerca de ese nuevo campo de objetos al que Baumgarten llama "conocimiento sensible perfecto". Pues sin semejante "estética natural" no podría haber ni tendría utilidad enmendadora alguna una "Estética artificial", la cual -como concluye atinadamente Meier- no constituye entonces más que "un comentario filosófico sobre la natural"9.

La propuesta de la Aesthetica, §140, de reducir la Tópica estética a una "sinopsis psicológica" no puede tomarse, por tanto, como una ocurrencia feliz y ocasional de Baumgarten, pero carente de relevancia en su proyecto filosófico y de trascendencia alguna en la historia de la Estética misma ${ }^{10}$. Forma parte más bien de un proceso histórico de formación de la modernidad, desde finales del siglo XVII hasta mediados del XVIII, en el que convergen dos grandes operaciones intelectuales al hilo de la disputa entre "antiguos y modernos": por un lado, la constitución de una subjetividad estética de la mano de la incipiente psicología empírica de origen cartesiano y/o lockeano, que conducirá al desarrollo de una "estética psicológica" o "patología estética", articulada sobre la fuerza viva de las emociones y los afectos ${ }^{11}$; y, por otro lado, la estetización de la retó-

${ }^{7}$ Cf. U. Franke, Kunst als Erkenntnis, pp. 83-85. Sobre este aspecto psicológico innato del sujeto estético, al que Baumgarten y Meier denominan "estética natural", véase nuestra anterior nota 5. Cf. G. F. Meier, Anfangsgründe, §§12 ss.

${ }^{8}$ G. F. Meier, Anfangsgründe, §12, p. 18; cf. §213, p. 506.

${ }^{9}$ Ibid., §12, p. 19.

${ }^{10}$ Esta idea de la Estética como una nueva Tópica de la invención basada en la psicología del sujeto creador ha pasado casi inadvertida a la historiografía sobre Baumgarten. Recientemente Pietro Pimpinella, "Hermeneutik und Ästhetik bei A.G. Baumgarten", en: M. Beetz / G. Cacciatore (Hg.), Die Hermeneutik im Zeitalter der Aufklärung, Köln/Weimar/Wien: Böhlau, 2000, p. 279, se ha hecho eco de ella, sin llegar a tematizarla.

${ }^{11}$ Sobre la idea de subjetividad estética v. "Ästhetische Subjektivität. Zu einem Grundbegriff moderner Ästhetik", en: G. von Graevenitz (Hg.), Konzepte der Moderne, Stuttgart/Weimar: Böhlau, 1999, pp. 593-611. Sobre el papel de la Psicología moderna en la Estética véase el célebre estudio de Robert Sommer, 
rica ${ }^{12}$, que conlleva o va unida, entre otras cosas, a la sustitución progresiva de la Tópica tradicional, basada en procedimientos socialmente estereotipados de invención (opiniones comunes, autoridades, fórmulas argumentativas...), por una Tópica ilustrada de la razón de base antropológica, que invoca frente al estrechamiento de la sociedad estamental y de sus convenciones culturales el poder liberador de la naturaleza humana y de su imaginación creadora, y contiene por ello una dimensión $u$-tópica, disolvente de cualquier lugar prefijado del pensar o constrictivo de la invención ${ }^{13}$.

Grundzüge einer Geschichte der deutschen Psychologie und Ästhetik von Wolff/Baumgarten bis Kant/Schiller, Würzburg, 1892. La evolución desde una Estética racionalista, de base metafísica, hacia una "Estética psicológica" hacia mediados del siglo XVIII en Alemania es, siguiendo la estela de Dilthey y Sommer, la tesis también de Alfred Baeumler, Das Irrationalitästsproblem in der Ästhetik und Logik des 18.Jahrhunderts bis zur Kritik der Urteilskraft [1923], Darmstadt: WBG, 1967. La consideración de Baumgarten como un racionalista estético por parte de Sommer y de Baeumler ha impedido ver la importancia de la Psicología empírica en su planteamiento estético hasta prácticamente los años setenta del pasado siglo y ha podido contribuir al silencio historiográfico sobre la propuesta de una Tópica natural de base psicológica. Sobre la idea de una patología estética, ya en Baumgarten, v. Dieter Kliche, “Ästhetische Pathologie. Ein Kapitel aus der Begriffsgeschichte der Ästhetik", Archiv für Begriffsgeschichte, 42 (2001), 197-229.

12 Sobre este cambio dieciochesco de paradigma cultural de la Retórica a la Estética v. Eberhard Ostermann, Die Authentizität des Ästhetischen. Studien zur ästhetischen Transformation der Rhetorik, München, W. Fink, 2002 (sobre el papel de Baumgarten, pp. 71-88). En este tema las posiciones oscilan entre los partidarios de la tesis de la continuidad o pervivencia de la Retórica en la Estética, aun bajo mutaciones notables (K. Dockhorn, M. Beetz, W. F. Bender, J. Dyck, incluso el propio E. Ostermann...), y los defensores de la disolución o desplazamiento definitivo de la una por la otra (H. Schanze, G. Ueding, P. D. Krause...). Sobre el lugar de Baumgarten en este debate, el monográfico coordinado por Christoph Menke, Schwerpunkt: Zur Aktualität der Ästhetik Alexander Gottlieb Baumgartens, en: Deutsche Zeitschrift für Philosophie 46:2 (2001), 229-298, lo sitúa dentro de la primera línea de interpretación como un reconstructor de la Poética y Retórica heredadas conforme a las formas de pensar modernas (p. 230). A la línea de interpretación contraria lo adscribe, en cambio, Heinrich Niehues-Pröbsting, "Rhetorik und Ästhetik", Rhetorik. Ein internationales Jahrbuch, 18 (1999), pp. 44-61, para quien Baumgarten, a pesar de haber partido de la Poética y Retórica tradicionales en su teoría del arte, contribuye, sin embargo, con su Estética a "la exclusión de la Retórica" (p. 48). Una escueta panorámica de los trabajos recientes sobre este tema en Baumgarten puede hallarse en Ursula Franke, "Sinnliche Erkenntnis - was sie ist und was sie soll. A. G. Baumgartens Ästhetik-Projekt zwischen Kunstphilosophie und Anthropologie", Aufklärung 20 (2008), 73-99, en concreto pp. 95-96.

${ }^{13}$ Sobre este cambio de paradigma topológico v. Lothar Bornscheuer, "Die 
La posición o contribución de Baumgarten a este surgimiento histórico de una Estética de la subjetividad individual, que erige la psicología de las sensaciones en procedimiento utópico de creación artística y fuente de placer estético, es difícil de determinar dentro de los esquemas de simplificación historiográfica al uso, si bien cabría calificarla, en cierto modo, de moderada. Su peculiaridad puede sintetizarse en dos ideas básicas. En primer lugar, la subjetivación estética del arte y de la belleza que implica la propuesta de una Tópica psicológica del artista, está lejos todavía de ser la apuesta por una utopía creadora de la sola imaginación y de las emociones inmediatas, tal como se desarrollará desde mediados del siglo XVIII (Sulzer, Herder, Moritz...); constituye, por el contrario, la defensa de una auténtica Tópica natural, de un procedimiento común de invención artística que confía, no obstante, la producción objetiva de belleza a un funcionamiento reglado de las propias facultades sensibles del alma humana. Mas ello se debe, en segundo lugar, a que la posibilidad de semejante Tópica natural de la invención descansa -tal es la convicción última que la hace plausible en Baumgarten- en unas bases monadológicas y teodiceicas de raíz leibniziana (más que wolffiana) que permiten al profesor de Frankfurt am Oder propugnar una racionalidad específica de lo sensible así como sostener su despliegue armónico y concordante en una dirección objetiva (perfección de los fenómenos) y en otra subjetiva (perfección de las facultades inferiores del alma). No es casual en este aspecto que incluso los seis criterios objetivos de belleza, que determinan ya la tipología de los argumentos y de las figuras estéticas, se exijan también como virtudes o cualidades psíquicas del sujeto creador $^{14}$. Debido a este fundamento metafísico común la Tópica subjetiva o psicológica se halla, pues, ligada a la Tópica objetiva o argumentativa.

Sobre ese trasfondo de supuestos metafísicos que en última instancia la sostienen, es preciso, sin embargo, poner aquí en primer plano la idea misma de una Tópica natural de la invención, para tratar de comprender cómo se elabora conceptualmente en la obra de Baumgarten, qué compromisos doctrinales lleva consigo y cuál es su verdadero alcance y limi-

Aufklärung der Topik und die Topik der Aufklärung”, en: S. Jüttner / J. Schlobach (Hg.), Europäische Aufklärung(en): Einheit und nationale Vielfalt, Hamburg: F. Meiner, 1992, pp. 54-65, espec. 62 ss.

${ }^{14}$ Así, por ejemplo, las Secciones XII (\$§149-157) y XXIV-XXVI (\$§352-422) de la Aesthetica están dedicadas respectivamente a la ubertas aesthetica personae y a la magnitudo aesthetica personae (= gravitas et magnanimitas aesthetica). Sobre este punto v. P. Pimpinella, "Hermeneutik und Ästhetik...", o.c., p. 280; y Dagmar Mirbach, "Ingenium venustum und magnitudo pectoris. Ethische Aspekte von Alexander Gottlieb Baumgartens Aesthetica”, Aufklärung, 20 (2008), pp. 199-218. 
taciones dentro del proceso creativo del arte. En el susodicho $\$ 140$ de la Aesthetica parece plantearse, no obstante, una doble Tópica natural: la del sujeto estético innato ("espíritu bello"), que se define en la Sección II de la obra; y la de la Psicología empírica, que se desarrolla en la Metaphysica, P. III, cap. 1. Ahora bien, como el espíritu bello no es más que la concreción ideal en un individuo ejemplar del conjunto de las facultades cognoscitivas sensibles del alma en una proporción e intensidad superiores a las normales, la posibilidad de una Tópica natural depende por entero del análisis de la facultas cognoscitiva inferior que Baumgarten nos ofrece en su Psychologia empirica, y, en concreto, de la correspondiente caracterización de sujeto del conocimiento sensible allí expuesta, de la cual el sujeto estético natural constituye tan sólo su figura de excelencia.

Por ello el objetivo de este artículo es examinar la noción de sujeto psíquico sensible que sirve de base a la Tópica natural de la invención artística. Obviamente, de ese sujeto forma parte el elenco de facultades inferiores de conocer que Baumgarten aborda en su Psicología empírica, pero su condición de sujeto psíquico viene dada por una de ellas, que constituye la instancia de unidad y dirección operativa de todas ellas: el sentido interno. Mostraremos a este respecto cómo Baumgarten lo habilita filosóficamente como fuente creadora del arte y lo convierte en el modo privilegiado de acceso cognoscitivo a la verdad metafísica del mundo. Este estatuto especial depende, sin embargo, de una cualificación gnoseológica que habilita teleológicamente el proceder de todas las facultades psíquicas y, con ello, al sujeto sensible para la producción y aprehensión de belleza. A esa perfección inherente a la sensibilidad humana, regida por el sentido interno, Baumgarten la denomina analogon rationis; un concepto que está asimismo en el núcleo de su caracterización del sujeto estético como "espíritu bello" (ingenium venustum). Con estas dos nociones -la de "sentido interno" y la de "análogo de la razón"- tenemos las dos piezas teóricas esenciales que permiten hacer del sujeto psíquico sensible el fundamento de una Tópica natural de la invención artística. Pero antes de examinarlas detenidamente, es preciso referirse al paradigma "psicológico" de la modernidad, en cuyo horizonte se sitúa Baumgarten al elaborar su noción de sujeto sensible y que toma como base de referencia científica para su Estética.

\section{2. "Sensaciones claras". La perspectiva del sujeto en la "Psicología Empírica de los Modernos"}

La creencia de Baumgarten en la posibilidad de una Tópica natural de la invención artística se basa en los avances científicos, entonces recientes, de la Psicología moderna. "La psicología empírica de los 
modernos" -afirma ya en 1741- proporciona un conocimiento del alma humana -y particularmente de la sensibilidad-, bastante mejor del que enseñaban los "antiguos" o podía obtenerse "de manera incierta y borrosa" por experiencia propia ${ }^{15}$. Formaba parte de la conciencia cultural de la época, tal como Baumgarten pudo conocerla dentro de su propio ambiente estudiantil, la convicción de que la nueva psicología basada en la experiencia había roto con la inútil concepción del alma heredada desde antiguo y se había "deshecho felizmente de su cacharrería verbal" ", apilada en torno a la célebre teoría aristotélico-escolástica de las tres almas (anima vegetativa, sensitiva, intelectiva sive rationalis). $\mathrm{Y}$ era asimismo opinión común que Descartes había llevado a cabo semejante giro copernicano en el pensamiento psicológico gracias a la sustitución de la concepción aristotélica del alma como entelequia vital por la de subjetividad humana o "conciencia", tal como se desprendía de su doctrina del cogito. Con su peculiar recepción del cartesianismo, Christian Wolff había otorgado su sello científico-sistemático a esta visión moderna del alma y la había habilitado en la cultura germánica con la publicación de su Psychologia empirica en 1732, en la cual se partía precisamente del nuevo concepto subjetivo de anima o mens (exclusivamente humana), entendida como conciencia de sí y de las cosas externas ${ }^{17}$.

15 [A. G. Baumgarten], Philosophische Briefe von Aletheophilus, 2. Schreiben, Frankfurt/Leipzig, 1741, p. 7. [= Philosophische Briefe]. Cf. Kollegium §1, p. 65; $\S 80$, p. 116.

${ }^{16}$ Ch. Wolff, Deutsche Logik, cap. 9, §3, citado según U. Franke, Kunst als Erkenntnis, p. 68. G. B. Bilfinger, compañero de estudios de Baumgarten, había criticado la psicología antigua en sus Dilucidationes philosophicae de 1725 . Sobre los orígenes de la Psicología Empírica moderna y su recepción en Baumgarten, v. U. Franke, Kunst als Erkenntnis, pp. 67 ss., y Friedhelm Solms, Disciplina aesthetica. Zur Frühgeschichte der ästhetischen Theorie bei Baumgarten und Herder, Stuttgart: Klett-Cotta, 1990, pp. 97-98; también R. Sommer, o.c., pp. 1 ss.

17 "Se llama alma a ese ente que en nosotros es consciente de sí y de las otras cosas fuera de nosotros. Se denomina por eso también alma humana, y asimismo mente o mente humana" (Ch. Wolff, Psychologia empirica, methodo scientifica pertractata, ed. Jean École, Gesammelte Werke, II. Abteilung: Lateinische Schriften, Hildesheim: Olms, 1968, vol. 5, §20, p. 15). Sobre el pensamiento psicológico de Ch. Wolff v. Olivier-Pierre Rudolph / Jean-François Goubet (Hg.), Die Psychologie Christian Wolffs. Systematische und historische Untersuchungen, Tübingen: M. Niemeyer, 2004.

Baumgarten se hace eco de esta concepción cartesiano-wolffiana del alma en el capítulo de "Psychologia empírica" de su Metaphysica, § 504: "Si en un ente hay algo que puede ser consciente de algo, eso es un alma" (Manejamos la edición de A. G. Baumgarten, Metaphysica, en: Kant's gesammelte Schriften, Berlin/Leipzig, 1923, vol. XV.1, p. 5) [= Metaphysica]. [Nota del autor: en este artículo todas las traducciones del latín o del alemán son responsabilidad mía]. 
Para hacerse una idea más precisa de lo que Baumgarten entiende por "psicología empírica de los modernos" y lo que considera su contribución decisiva al conocimiento de la sensibilidad humana, hay que tener en cuenta, no obstante, además de la corriente cartesiana su recepción de otras dos líneas de desarrollo de la doctrina del alma: por un lado, la empirista de origen lockeano, bien acogida en los ambientes pietistas de Halle, que suponía una revalorización de las sensaciones y con ello el reconocimiento de una subjetividad sensible, que no sólo percibe o siente el mundo externo a través de los sentidos, sino también sus propias "operaciones internas"18; y, por otro lado, la línea leibniziana de la concepción monadológica del alma como vis repraesentivae universi, que acreditaba la interioridad como fuente inagotable de conocimiento del mundo, y rehabilitaba además para el sujeto moderno la vieja concepción teleológico-aristotélica de la energeia y la entelequia al entender todo acto representativo o cognoscitivo como la actualización de una fuerza propia $^{19}$, que sacaba a relucir la perfección divina del universo. La confluencia de estas tres líneas de la psicología moderna en el pensamiento de Baumgarten se traducirá en la definición de un sujeto sensible sobre el primado del "sentido interno" como base psíquica natural del sujeto estético y fundamento último de la nueva ciencia del conocimiento y la representación sensibles. Trataremos de demostrar a continuación esta tesis analizando cuáles son, para Baumgarten, los méritos de la psicología empírica de los modernos y cuál el concepto de sensibilidad que se deriva de ahí y sobre el que elabora su visión de la Estética.

En la Segunda Carta de las Philosophische Briefe von Aletheophilus (1741) puede leerse lo siguiente a propósito de lo que, según Baumgarten, constituye el saber de su época sobre la experiencia humana:

De entrada parece como si en este asunto no pudiera decirse mucho más que esto: ¡abre tus ojos y mira!; ¡abre tus oídos y escucha!, etc. Sólo quien conozca algo más a fondo la índole de las sensaciones [die Beschaffenheit derer Empfindungen], tendrá un juicio completamente distinto. Pues las hay tanto internas como externas. Las primeras son las representaciones del estado interno actual de nuestra alma. Todos nosotros las tenemos. Pero que en uno son mejores, en otro peores,

${ }^{18}$ John Locke, Ensayo sobre el entendimiento humano [1690], Madrid: Editora Nacional, 1980, Libro II, cap.1, §2 y §4, pp. 164-165.

${ }^{19}$ La recepción de la concepción dinámico-monadológica del alma por Baumgarten es clara en su Metaphysica, §506: "Los pensamientos son representaciones. Luego mi alma es fuerza representativa"; y $§ 507:$ "Mi alma piensa al menos ciertas partes de este universo. Luego mi alma es fuerza representativa de este universo, al menos parcialmente" (Metaphysica, p. 6). 
esto lo prueba la psicología empírica de los modernos, comparada con lo que antes de ellos se ha enseñado acerca del alma, o lo que se ha observado de manera bastante borrosa e incierta a través del simple ejercicio y trato con ella. ${ }^{20}$

La principal enseñanza de la psicología moderna con respecto a la sensibilidad es, pues, la distinción de origen lockeano entre sensaciones externas e internas $y$, por tanto, entre un sentido externo y un sentido interno. Mediante aquél, según Baumgarten, el sujeto se representa el estado actual (praesens) de su cuerpo gracias al movimiento de los órganos sensoriales; mediante éste, en cambio, el sujeto percibe el estado actual de su alma, siente o toma conciencia de sus propios actos psíqui$\cos ^{21}$. Sobre la base de esta distinción específica de la facultas sentiendi o sensus, el concepto más amplio y general de sensibilidad como "facultad inferior de conocer" (facultas sensitiva) y el de conocimiento sensible (cognitio sensitiva) introducidos por Baumgarten ${ }^{22}$ parece que abarcarían, por un lado, el ámbito del conocimiento empírico del mundo externo a través de los sentidos (experiencia común y científica) y, por otro lado, el ámbito de la experiencia interna, propiamente psicológica, del alma humana. Esta noción general de lo sensible es la que se halla en el proyecto inicial de la Estética como nueva filosofía orgánica o lógica de la sensibilidad en la época de Halle ${ }^{23}$, la que corresponde asimismo al otro sentido de la derivación etimológica del término por parte de Baumgarten, el de la $\alpha \_\vartheta \eta \sigma \mathrm{s}$, por el cual la Estética (en cuanto Aisthetica) se presenta como una teoría de todo tipo de percepción o representación sensible ${ }^{24}$ (no sólo de la representación artística o bella), y

${ }^{20}$ [A. G. Baumgarten], Philosophische Briefe von Aletheophilus, o.c., pp. 7-8. Cf. Kollegium \$1, p. 65.

${ }^{21}$ Cf. A. G. Baumgarten, Metaphysica, §535: "Tengo la facultad de sentir, es decir, el sentido [sensus]. El sentido representa o el estado [actual -cf. §534] de mi alma (interno) o el estado de mi cuerpo (externo). De ahí que la sensación [sensatio] sea o interna, cuando es activada a través del sentido interno (conscientia strictius dicta), o externa, cuando es activada por el sentido externo" (o.c., p. 13).

${ }^{22}$ Cf. Metaphysica, $\$ \$ 20-521$. Sobre este tema y la diferencia en Wolff y Baumgarten véase el magnífico artículo de Pietro Pimpinella, "Sensus e sensatio in Wolff e Baumgarten", en: Wolff e Baumgarten. Studi di terminologia filosofica, Firenze: L.S. Olschki, 2005, pp. 41-68.

${ }^{23}$ Es el planteamiento de la Metaphysica $\left(1739,1742^{2}\right)$, §533, las Philosophische Briefe von Aletheophilus (1741), pp.7-8, y la Philosophia generalis (1742, publicada póstuma en 1770), §147.

${ }^{24}$ Sobre el significado de sentio y $\alpha \_\vartheta \uparrow v 0 \mu \alpha$ como "percepción sensible" v. Kollegium, §1, p. 65; pero ya también Meditationes philosophicae de nonnullis ad poema pertinentibus, §CXVI [= Meditationes. Manejamos la edición bilingüe de 
la que le lleva igualmente a plantear, por lo que al sentido externo se refiere, el plan concreto de una "Estética empírica", encargada de estudiar las leyes de funcionamiento de nuestros sentidos para mejorar y ampliar la claridad cognoscitiva de la experiencia externa ${ }^{25}$.

Sin embargo, como es bien sabido, aquel primer proyecto de una gnoseologia inferior que diera cuenta de todo el amplio campo del conocimiento sensible, quedó reducido en la inacabada Aesthetica de 1750-58 a una teoría de lo bello y de la creación artística, en la que no se tematiza el conocimiento empírico del mundo sino únicamente el conocimiento propiamente estético, sin duda debido a que sólo la belleza constituye la perfección específica de lo sensible (perfectio phaenomenon), que Baumgarten, ya desde las Meditationes de 1735, vinculó al criterio de la "claridad extensiva" de las representaciones ${ }^{26}$. Ahora bien, para los fines de la explicación y fundamentación del conocimiento propiamente estético (o bello) poco importa la experiencia externa de las cosas como tales y la claridad (intensiva) con la que nos representamos objetivamente el mundo fuera de nosotros mediante los órganos sensoriales; interesa más bien el modo como los fenómenos externos afectan a nuestros sentidos corporales y activan al sujeto humano, poniendo en marcha su interioridad psíquica. Desde esta perspectiva psicológica, en la cual las representaciones son consideradas sólo como cambios subjetivos de estado (mutationes status animae), las cosas del mundo no entran en juego, en rigor, como objetos cognoscitivos de percepciones sensibles ("sinnliche

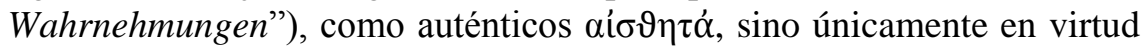
de las claras sensaciones ("klare Empfindungen") que dejan en nuestro cuerpo y que conllevan obviamente modificaciones de nuestra alma ${ }^{27}$. En

H. Paetzold en Hamburg: Meiner, 1983]. Sobre la idea recientemente reivindicada de una Aisthetica v. Dieter Kliche, "Ästhetik und Aisthesis. Zur Begriffs- und Problemgeschichte des Ästhetischen”, Weimarer Beiträge, 44 (1998), p. 492 ss.; y sobre las perspectivas antropológicas y filosófico-culturales ligadas a ella v. Steffen W. Gross, Felix Aestheticus. Die Ästhetik als Lehre vom Menschen, Würzburg, Königshausen \& Neumann, 2001, espec. 163 ss.

${ }^{25}$ Sobre la "Estética empírica", v. Metaphysica, §544; Philosophische Briefe, pp. 78; y Philosophia generalis (2. ${ }^{\text {a }}$ reimpresión de la edición de 1770 en Hildesheim/Zürich/New York: Olms, 2002), §147, p. 52. El objetivo de esta "Estética empírica", que debía fomentar también el desarrollo y uso de los instrumentos técnicos que amplían nuestra capacidad sensorial, era lograr la "claridad intensiva" del conocimiento sensible (v. Pietro Pimpinella, "Sensus e sensatio...", o.c., p. 63).

${ }^{26}$ Cf. Meditationes, §XVI. También Metaphysica, §531.

${ }^{27}$ Para Baumgarten, a diferencia de Wolff, la objetividad de nuestras representaciones del mundo externo no es un problema gnoseológico, ya que viene garantizada por el "sistema universal de la armonía preestablecida", que Wolff, sin 
este aspecto, las sensaciones externas son también subjetivas, puesto que en cuanto cogitationes o actos representativos constituyen igualmente "accidentia animae meae", aunque se refieran a cambios corporales ${ }^{28}$. De ahí que el tratamiento del sentido externo y de los órganos sensoriales, ya en la "Psicología empírica" de Baumgarten pero aún más nítidamente en su Aesthetica, sólo sirva para "hacer plausible su función mediadora" y propiciadora del "retorno permanente del alma a sí misma"29.

embargo, no acepta más que en la versión restringida de la relación alma-cuerpo. En realidad, el alma humana, al conocer, no sale de sí misma, no entra en contacto con los objetos del mundo (ni está determinada por la presencia física de éstos); su receptividad en las sensaciones externas es sólo receptividad con respecto al propio cuerpo (cf. P. Pimpinella, "Sensus e sensatio...", o.c., p. 58), cuya posición en el mundo marca ciertamente la perspectiva parcial de las representaciones del alma, sin menoscabar, empero, su autarquía representativa. En su tratamiento del conocimiento sensible y, particularmente, del sensus Baumgarten se aleja de Wolff debido a la asunción de doctrinas lebnizianas que el autor de los Vernünftige Gedanken nunca vio con buenos ojos: entre ellas, la monadología y el sistema universal de la armonía preestablecida (cf. P. Pimpinella, o.c., pp. 56 ss.), indispensables para la fundamentación metafísica de su Estética y, en concreto, de su idea de la creación artística.

${ }^{28}$ Cf. Metaphysica, §505: "Pienso, luego se modifica mi alma. Por tanto, los pensamientos son accidentes de mi alma..." (p. 6). Para Baumgarten son equivalentes cogitatio, repraesentatio y perceptio: se trata siempre de un cambio o modificación del estado del alma y, por ello, de un accidente. Sobre el carácter subjetivo de las sensaciones externas en cuanto cambios del alma relativos a cambios de estado del propio cuerpo, es indicativo que Baumgarten tradujese "corpus meum" por mein Leib en vez de por Körper, término alemán que reservó para los restantes cuerpos (corpora) del mundo (cf. Metaphysica, §508, p. 6). Pero ya en su escrito juvenil se refirió, sin distinción alguna, a las "sensaciones" en general -denominadas allí sensuales-como "representaciones de cambios actuales del sujeto representante" (Meditationes, §XXIV), e incluyó entre ellas los "afectos" mismos. Como es bien conocido, desde la perspectiva psicológica desde la que se afrontaba incluso la cuestión del conocimiento del mundo hasta mediados del siglo XVIII, todo "contenido de conciencia" se consideraba un "dato inmediato de vivencia" (U. Franke, Kunst als Erkenntnis, p. 67), por lo que no solía haber una distinción clara entre sensaciones, sentimientos, afectos e incluso percepciones sensibles.

${ }^{29}$ F. Solms, Disciplina aesthetica, o.c., p. 100. Aunque en su "Psychologia empirica" Baumgarten aborda ciertamente la sensación externa desde la perspectiva de la "claridad intensiva" del conocimiento empírico (experientia), incluyendo aquí el problema del supuesto "engaño de los sentidos" (Metaphysica, $\S \$ 536-540,543$ ss.), también la examina ya desde el punto de vista predominante tanto en la sección primera, introductoria ("Existentia animae"), como en la sección segunda, dedicada a la "Facultas cognoscitiva inferior" en general: la perspectiva de la fuerza de las representaciones, es decir, de su poder para modificar el estado del alma (perceptio praegnans), que depende más de la 


\section{El Sentido interno, la Forma del sujeto psíquico: "sentimiento interno", Conscientia intima}

Sin abandonar su concepto general de sensibilidad, identificada psicológicamente con la facultad inferior de conocer, Baumgarten lo deja, sin embargo, en un segundo plano en el proceso de construcción y redacción de su Aesthetica, y en su lugar maneja y elabora la noción específica que sirve a los fines particulares del conocimiento estético, y que podía extraer únicamente de la Psicología empírica (no de la Fisiología, la Óptica u otras ciencias naturales de la época), a saber, la de sentido interno $^{30}$. Nuestras consideraciones precedentes así lo indican, pero hay, no obstante, una referencia textual en el Curso de Estética editado por B. Pope que muestra esto con claridad: es el $\$ 29$, que plantea en concreto el tipo y la índole del sensus o facultas sentiendi con la que debe contar de manera innata, y en alto grado, un "espíritu bello". Baumgarten exige ahí "sentidos agudos" (scharfe Sinne), pero entiende por tales no tanto la agudeza de los órganos sensoriales (ojos, oídos, nariz, paladar...) para la percepción de objetos, cuanto más bien la cualificación de los sentidos para "producir en él [el espíritu bello] sensaciones claras y vívidas", que "le sirvan para adquirir una reserva de pensamientos bellos", de tal suerte que, una vez provisto de esta "materia estética" (Stoff zum Schönen), pueda seguir creando belleza aun cuando los "órganos externos de los sentidos" se le hayan deteriorado por completo, como les ocurriera a "Homero y a Milton". Se requiere, en suma, un "sentimiento interno" (das innere Gefühl) "especial y poderoso", que, lejos de encontrar su caldo de cultivo apropiado en una vida disipada de diversión y hedonismo, tiene en la estimulación excesiva de los órganos sensoriales su fuente de corrupción, ya que la presencia constante de "sensaciones" y "sentimientos" externos "demasiado fuertes" obstruye o da al traste "con las ocurrencias bellas" ${ }^{31}$. La facultad de sentir (sensus, Sinn) que Baumgarten

oscuridad que de la distinción y que, para ser estética, debe formar parte de la “claridad extensiva" (cf. Metaphysica, $\$ \$ 516-517,531-532$; y con respecto a las "sensaciones externas", $\S 537$ ss., 542-543, 549-551). Esa fuerza representativa constituye la clave de la argumentación estética (cf. Aesthetica, §26). A la vista de este enfoque subjetivo de las sensaciones no es casual que Kant, en una anotación de su manuscrito docente de la Metaphysica $\left(1757^{4}\right)$ de Baumgarten a la altura del título de la sección III, identificara el sensus o facultas sentiendi con el "sentido interno" ["Vom innern Sinn"] (cf. R 123, AA XV.1, p.16).

${ }^{30}$ El mejor tratamiento de este tema, poco analizado en la historiografía, se halla en U. Franke, Kunst als Erkenntnis, pp.69-71; y brevemente en "Sinnliche Erkenntnis...”, pp. 80-82; también F. Solms, o.c., pp. 98 ss.

31 Kollegium, §29, pp. 86-87. Baumgarten dice literalmente que "el sentimiento 
pone en la base de su noción psicológica de sensibilidad como fuente estética, no es, pues, más que la capacidad del sujeto humano para asimilar cognitiva y emotivamente a la vez cuanto acontece en cada momento dentro y fuera de él, en su interior y en su propio cuerpo; una capacidad que en el "espíritu bello" ha de tener un alto grado de intensidad. Al tratarse de una facultad de interiorización afectiva de cualquier contenido perceptivo, en virtud de la cual lo representado es siempre puesto en relación con el sujeto psíquico antes que con el objeto, Baumgarten lo denomina "sentimiento", un término que aquí se usa como equivalente al de "sentido", puesto que se habla tanto de uno "externo" (ligado al placer corporal) como de uno "interno" (concerniente al placer del alma). Sentido (sensus, Sinn) y sentimiento (Gefühl), sensación (sensatio, Empfindung) y emoción o afecto (affectus, Rührung) son nociones -como es sabido- apenas discernibles en la época de Baumgarten, antes de la estricta tripartición kantiana de las facultades antropológicas: facultad de conocer, de sentir y de apetecer. Comoquiera que sea, el concepto de sensibilidad que se reivindica en el §29 del Curso de Estética a propósito del sensus, concierne únicamente al sentido o sentimiento internos.

A raíz de la cita precedente surge la cuestión de saber qué es propiamente el sentido interno. Resulta evidente que no es el conjunto o suma de las facultades inferiores de conocer que Baumgarten propone, revisando y ampliando el catálogo de la Psychologia empirica de Wolff, en el capítulo correspondiente de su Metaphysica (sensus, phantasia o imaginatio, perspicatia [ingenio y agudeza conjuntamente], memoria, facultas fingendi, praevisio, iudicium sensitivum [gusto estético] y facultas characteristica $)^{32}$. Ahora bien, si -como parece desprenderse de ese capítulo y del $\$ 29$ del Curso de Estética- el sensus internus o das innere Gefühl fuera únicamente una más entre esas capacidades inferiores del alma humana, ¿cómo podría entonces identificarse la sensibilidad en general con una sola de sus facultades o, mejor, por qué habría de calificarse de sensible (sensitiva) toda la facultas cognoscitiva inferior sobre la base de una de ellas -el sensus-, entendida como sentido interno? En una

externo corrompe el interno". Como prueba de ello menciona el caso habitual de individuos de talento natural que han perdido su disposición estética al entregarse a las diversiones de la Corte. La idea de fondo que explica este hecho es que las sensaciones en general, y particularmente las sensaciones externas son siempre, por su alto grado de oscuridad, más fuertes (cf. Metaphysica, §517) que cualquier otro tipo de representaciones sensibles, por lo que normalmente debilitan o anulan a éstas (cf. Metaphysica, §542); ellas rompen ese cierto equilibrio entre claridad y fuerza de las representaciones que es inherente a la belleza, como perfección fenoménica, y para cuya aprehensión debe estar también dotado el sujeto estético.

${ }^{32}$ Cf. Ästhetik, §§30-37; Kollegium, §29-37; y Metaphysica, P. III, cap. 1, Sect. III-XI. 
palabra: ¿por qué y hasta qué punto la sensibilidad, como noción "estético-psicológica" -llamémosla así-, es o se basa en el sentido interno?

Hay que constatar, en primer lugar, la ausencia de una teoría elaborada sobre el sentido interno por parte de Baumgarten. Tampoco ayuda mucho la reflexión al respecto, aún más breve y ocasional, de su autor de referencia en la Psicología empírica, Christian Wolff, más interesado en los problemas del sentido externo ${ }^{33}$. La relevancia que, sin embargo, el sentido interno adquiere para Baumgarten en el proceso psicológico de la creación artística contrasta con su escasa tematización teórica, reducida a un par de textos algo oscuros y borrosos conceptualmente, cargados de presupuestos sin aclarar. Aparte de la simple definición, más arriba citada, de Metaphysica, §535, lo dedicado al tema está condensado en los dos únicos fragmentos que se transcriben a continuación como documentos ilustrativos de nuestro análisis.

En él mismo [el espíritu bello] debe dominar un sentimiento especialmente poderoso y una conciencia interna, que opera en él; de lo contrario, se moverá sólo como una máquina y no estará en condiciones de juzgar correctamente pensamientos bellos. La finura en el juicio exige especialmente el sentimiento interno; de lo contrario, no se encontrará en algunos casos la medida apropiada, la que es apta para mi persona y para cualquier otra, y que será también útil para ciertos espíritus melancólicos, que no saben mantener medida alguna en la aflicción.

Este sentimiento interno debe hacer más que todo el externo. Quien sólo tiene ojos y oídos, nunca llegará a ser un espíritu bello. El sentimiento interno nos diferencia de los animales. Un perro que ha estado de viaje con su dueño, tiene en muchos aspectos mejor sentimiento externo que él; únicamente el sentimiento interno de lo que ha visto es para el dueño con creces mucho más fructífero. ${ }^{34}$

Al espíritu bello [ingenium venustum] del que se habló en el $\$ 29$ corresponden A) las facultades inferiores de conocer y sus disposiciones naturales: a) la facultad de sentir agudamente [acute sentiendi] (M. §540), no sólo para que el alma obtenga de los sentidos externos la materia prima para pensar de modo bello, sino también para que mediante el sentido interno y la conciencia íntima [sensu interno, intimaque conscientia] (M. \$535) pueda experimentar los cambios y efectos de sus restantes facultades a fin de dirigirlas [directura]. Para que la facultad de sentir coopere normalmente con todas las restantes, ha de darse en el espíritu bello en tal medida que

${ }^{33}$ V. P. Pimpinella, “Sensus e sensatio...”, o.c., pp. 44 ss.

${ }^{34}$ Kollegium, \$29, p. 86. 
con cualesquiera de sus sensaciones no anule siempre y por doquier cualquier pensamiento que sea heterogéneo con respecto a ellas. ${ }^{35}$

En estos textos salta a la vista, en segundo lugar, que para Baumgarten el sentido interno no es una capacidad más del alma, que se añada al elenco de la facultas cognoscitiva inferior como cualquier otra facultad y cumpla dentro de ella una función meramente parcial en el proceso del conocimiento sensible. Estamos, por el contrario, más bien ante una fuerza concurrente con cada una de las operaciones psíquicas de percepción, ya que se hace presente en ellas, al hacerlas de algún modo objeto de representación y permitir así al alma "experimentar (experiri) los cambios y efectos de las restantes facultades". Aunque Baumgarten no lo dice expresamente, el sentido interno opera también en la sensación externa, pues el sujeto no podría asimilar, hacer propio el efecto de representarse el estado actual del cuerpo sin estar ipso facto presente. Baumgarten, sin embargo, no deja clara esta diferencia entre la (co)presencia del sujeto representante y la presencia de lo representado. Su distinción internus/externus, predicada del sensus y de la sensatio, se basa en lo segundo ${ }^{36}$; en cambio, cuando habla de das innere Gefühl en el Curso de Estética, \$29, tiene también en mente lo primero, puesto que con ese "sentimiento interno" alude a una capacidad del sujeto de hacer suyo o sentir cuanto se representa el alma, esté o no presente lo representado, y esa apropiación sólo es posible si él comparece al mismo tiempo en cada representación. La importancia de este sentir concurrente en cada acto representativo es tal que Baumgarten cifra en él lo específicamente distintivo del hombre frente a los animales. Podríamos -cabría argüir ad hominem - carecer de imaginación o de memoria o incluso de algún sentido externo (como el ciego Homero o el sordo Beethoven), pero no de ese sentimiento interno y pretender a la vez seguir siendo seres humanos (y aún menos artistas).

El hecho de constituir, por así decir, la seña de identidad propia de la especie humana, indica, en tercer lugar, que el sentido interno tiene que ver entonces con lo peculiar del anima, ya que el hombre se distingue por ser un ente que además de un cuerpo posee, en "comercio con él", tam-

35 Ästhetik, §30.

${ }^{36}$ Cf. Metaphysica, \$535. Lo peculiar del sensus y de la sensatio a diferencia de otras facultades es la representación de "estados míos presentes" (\$534). Con el énfasis en la distinción entre esos estados presentes (status animae meae / corporis mei) se desplaza la atención de la co-presencia del sujeto representante, mentada en el meum ("mío/mía"), a la presencia de lo representado, y de este modo aquélla queda oculta. 
bién un alma ${ }^{37}$. Baumgarten no duda por ello en calificar el sentido interno de "conscientia strictius dicta" ciencia, una conciencia que él considera igualmente interna (conscientia intima, das innere Bewusstsein). Nos encontramos, por tanto, con dos predicados cuya combinación en la caracterización de un mismo fenómeno de la facultad representativa del alma resulta para un lector post-kantiano bastante chocante. Sentimiento y conciencia son, sin embargo, las dos notas que definen el sentido interno, y mediante ellas, en cuanto referidas a la interioridad del sujeto psíquico, no se alude, por cierto, a cualquier sentimiento o sensación concreta del alma humana (p.e., la alegría, la tristeza, la angustia...) ni a la conciencia particular de este o aquel movimiento representativo (p.e., el recordar, el prever, el imaginar...); por concurrir con cada una de estas operaciones subjetivas se trata más bien de un sentimiento y de una conciencia auto-referenciales, es decir, de un sentirse a sí mismo y ser consciente de sí el sujeto representante a través de o en cada acto perceptivo del alma. Cabe hablar, en este aspecto, de sentimiento o "sensación de sí mismo" (Selbstempfindung) y en cierto modo de "autoconciencia" (Selbstbewusstsein), aún no lógico-reflexiva sino inmediata, ligada directamente a la existencia misma del alma $^{39}$, a su presencia en el mundo. Sería una autoconciencia meramente sentiente o un sentimiento de sí que tiene a la vez la dimensión cognitiva de la conciencia. En esta difícil y problemática posición de equilibrio entre lo afectivo-emotivo y lo racional-cognoscitivo parece situarse la idea que Baumgarten tiene del sentido interno.

${ }^{37}$ Cf. Metaphysica, $\$ 740$.

${ }^{38}$ Ibid., §535. Recuérdese que la nota distintiva del alma es la "conciencia” (Ibid., $\$ 504)$.

39 Sobre esta interpretación del "sentido interno" y su "conscientia intima" como "Selbstempfindung" de carácter pre-reflexivo v. U. Franke, Kunst als Erkenntnis, pp. 70-71; y "Sinnliche Erkenntnis...", p. 82 nota 32 (el sentido interno es "una sensación de sí mismo (conscientia intima) que hay que entender en términos auto-reflexivos"); y F. Solms, Disciplina aesthetica, pp.98-99, 103. Hay aquí, ciertamente, una pieza clave, si bien aún poco elaborada, en la construcción filosófica de la idea auto-reflexiva de sujeto moderno, pero en sentido específicamente estético. Christoph Menke, centrado principalmente en la dimensión activo-productiva del alma como "fuerza", omite en su análisis del sujeto estético moderno esta dimensión pre-reflexiva de Baumgarten, vinculada también al concepto unitario de alma como vis (v. Christoph Menke, "Ästhetische Subjektivität...”, o.c., pp. 596-597; y "Wahrnehmung, Tätigkeit, Selbstreflexion: Zu Genese und Dialektik der Ästhetik", en: A. Kern / R. Sonderegger (Hg.), Falsche Gegensätze. Zeitgenössische Positionen zur philosophischen Ästhetik, Frankfurt am Main: Suhrkamp, 2002, pp. 19-48, espec. 37 ss.). 
En efecto, por un lado, no se trata de un mero sentimiento que el sujeto tiene de sí al actuar en el mundo ${ }^{40}$, pues ello eliminaría toda posibilidad de hallar sobre esa base un mínimo de unidad y racionalidad en lo sensible y de hablar siquiera de una cognitio sensitiva. Esta consecuencia radical es, sin embargo, la que sacará, como lector privilegiado de la Aesthetica y de la Metaphysica, el joven J. G. Herder de los años sesenta, al hacer del solo yo sentiente, sin conciencia lógico-cognitiva alguna, la evidencia primera y fundamental de la existencia del sujeto y del mundo ${ }^{41}$. Baumgarten entiende, sin embargo, que esa experiencia auto-sentiente del sujeto cuenta ya con el rasgo distintivo del alma: la conciencia, y que gracias a ello la sensibilidad humana tiene unidad y puede ser fuente de conocimiento válido, porque caben en ella-como veremos- reglas psíquicas de funcionamiento armónico y a la vez una aprehensión o representación de nexos fenoménicos de las cosas: ambos elementos son condiciones indispensables de la Estética como ciencia y como arte bello.

Ahora bien, como, por otro lado, la conciencia de sí del sentido interno no es lógico-intelectual (reflexiva), sino sólo sentiente, tanto las reglas psíquicas como los posibles nexos fenoménicos perceptibles difícilmente podrán fundar algo más que un conocimiento estrictamente subjetivo. Ésta será la conclusión que extraerá Kant, lector y estudioso de la Metaphysica de Baumgarten, para negar toda validez científico-cognoscitiva a la "Psicología empírica" y a la Estética fundada en ella. Obviamente el argumento kantiano se basa en que todo conocimiento objetivo descansa en una autoconciencia estrictamente intelectual, la "apercepción pura", que es "conciencia de lo que el hombre hace", no de lo que "padece" o siente; esto último define, sin embargo, al sentido interno, que, en este aspecto, sería sólo una "apercepción empírica"42. Baumgarten, en su noción de sentido interno, confunde o mezcla ambas cosas - tal es el reproche de Kant- para garantizar la validez cognoscitiva de la Psicología empírica y de la representación estética del mundo por

${ }^{40} \mathrm{Ni}$ el sentido interno ni las "sensaciones" en general son aún en Baumgarten meros sentimientos (Gefühle) (cf. U. Franke, Kunst als Erkenntnis, p. 71 nota 39; A. Baeumler, o.c., pp. 112 ss., 123 ss., quien subraya no sólo el "momento lógico"; también atribuye a la perspectiva de la "creación artística" (en vez de la del "goce" sensible) de su Estética el papel secundario de lo sentimental). Este giro reduccionista de lo estético a mera afección emotivo-sentimental del sujeto se inicia en Alemania en la década de los cincuenta y sesenta con Sulzer, Mendelssohn y Herder (v. A. Baeumler, o.c., pp. 117 ss.).

${ }^{41}$ Sobre esta interpretación herderiana v. F. Solms, Disciplina aesthetica, pp. 121 ss.

${ }^{42}$ Cf. I. Kant, Antropología en sentido pragmático, Madrid: Alianza, 1991, §24, p. $62 ; \S 4$, pp. $25-26$ nota. 
parte del sujeto. Mas su planteamiento es viable porque participa del supuesto metafísico-monadológico leibniziano que Kant ya no comparte: que el "padecer" del sujeto es al mismo tiempo su "hacer", pues sólo acaece como activación de la fuerza representativa del alma humana. El momento de la conciencia en el sentido interno indica precisamente que el sujeto humano no puede sentirse sin estar ipso facto actuando, poniendo en marcha, haciendo presente su vis sustancial. "Sensatio mea actuatur per vim animae repraesentativam...". 43 La convicción de Baumgarten de que es posible un conocimiento válido de lo "sentido" por el sujeto, aun cuando no sea un conocimiento lógico de lo "distinguido" (empírica o racionalmente) en el objeto, se funda en ese supuesto monadológico, al igual que también se apoya en él y en la doctrina teodiceica paralela del mejor mundo posible su creencia en que semejante conocimiento estético-subjetivo es representación verdadera del mundo real, rico en fenómenos, o actualiza algún aspecto suyo -algún mundo posible-, ya que el sujeto creador se limita a sacarlo a la luz desde el interior oscuro y confuso de su alma ${ }^{44}$.

A posibilitar precisamente esa cognitio sensitiva del sujeto estético, basada en reglas psíquicas, sirve, en cuarto lugar, la otra función que, junto a la auto-referencial o de concurrencia, Baumgarten atribuye al sentido interno como conscientia intima: la de ser una fuerza unificadora de toda la actividad fenoménico-representativa de la mente humana. Se trata, pues, no ya de "experimentar" (experiri) cada operación psíquica estando presente en ella; se trata, gracias a esta co-presencia constante, de la labor adicional de coordinación y de "dirección" de todas las restantes facultades con la que se garantiza tanto la unidad operativa de representación del alma humana como -lo veremos después- la correspondiente unidad argumentativa o nexo cognitivo de claridad estética de lo representado. Podría decirse en este aspecto, parafraseando a Kant, que el sentido interno constituye la unidad innata de apercepción psicológica; una unidad, sin duda, exclusivamente subjetiva -expresión de la fuerza

${ }^{43}$ Metaphysica, $\$ 534$ (esta fórmula se repite a propósito de cada facultad del alma). Sobre el "padecer" como "acción" v. P. Pimpinella, "Sensus e sensatio...", pp. 5758. Recuérdese que los actos representativos (cogitationes) son sólo accidentes y, en cuanto tales, efectos cuya razón suficiente (o causa) es la "fuerza" del alma misma como sustancia simple (cf. Metaphysica, §505).

${ }^{44}$ Sobre la "verdad estética", v. P. Pimpinella, "Veritas aesthetica. Erkenntnis des Individuellen und mögliche Welten”, Aufklärung, 20 (2008), pp. 37-68. Sobre este papel de la vis repraesentativa universi como fuente material (no sólo formal) de una obra de arte, en el que no podemos entrar aquí, puede verse, por ejemplo, U. Franke, Kunst als Erkenntnis, pp. 71-72. Sobre la importancia de la Teodicea para la Estética, véase más abajo. 
única del alma-, pero que, dada la armónica correlación entre el alma y el mundo, se hace eco y permite actualizar al mismo tiempo una unidad objetiva, aunque no de índole lógica sino estética. Esta función armonizadora del sentido interno, en cuanto forma de unidad psíquica y vehículo subjetivo de la actualización de los nexos fenoménicos de las cosas, es la que hace posible la labor cognoscitiva de la sensibilidad y la cualifica como analogon rationis.

Pero antes de presentar brevemente este concepto, conviene señalar, en quinto y último lugar, por qué Baumgarten ha encumbrado gnoseológicamente el sentido interno y ha convertido de este modo el arte y la experiencia estética en la principal forma de acceso a la verdad (metafísica) del mundo, como Herder muy bien llegara luego a sostener abiertamente. El motivo último se halla en una doble convicción profundamente anti-cartesiana (y poco wolffiana), de origen teodiceico-leibniziano y probablemente también pietista: la creencia, por un lado, en la veracidad absoluta de los sentidos, del sensus en general; y, por otro lado, el convencimiento de que sólo ellos, y la sensibilidad en general, nos ponen en contacto con la realidad metafísica del mundo, que es individual. Con respecto a lo primero Baumgarten declara enfáticamente que los sentidos nunca nos engañan, porque las sensaciones, en cuanto representaciones de lo que está presente, "perciben cosas actuales (actualia), o sea, cosas también posibles (possibilia) y que son ciertamente de este mundo; por tanto, son lo más verdadero del mundo entero (verissimae totius mundi) ${ }^{\natural 45}$. Y con respecto a la segunda convicción, Baumgarten participa de la idea leibniziana de que la realidad de este mundo es sumamente compleja y rica, pues está constituida por individuos (singularia), entes "omnímodamente determinados", que escapan a la simplificación abstracta del conocimiento racional y sólo pueden ser cognoscitivamente accesibles a través de la sensación, al precio, naturalmente, de la pérdida de nitidez lógica, esto es, de la inevitable confusión y oscuridad inherentes a la riqueza de notas de las cosas singulares que los sentidos nos hacen presentes ${ }^{46}$. El sentido interno, como principio o forma psicológica unitaria de la sensibilidad, se convierte así en fuente privilegiada de acceso a la realidad metafísica del mundo, y el conocimiento estético, en cuanto representación sensible de lo concreto e individual a partir del sentido interno, se eleva a la categoría de experiencia o expresión suma de la verdad. Sólo Kant, con su baconiano de nobis ipsis silemus, romperá

${ }^{45}$ Metaphysica, \$546. Sobre este tema de la sensibilidad como conocimiento verdadero de lo individual, véanse los artículos citados de Pietro Pimpinella sobre el sensus y sobre la veritas aesthetica.

46 Cf. Metaphysica, \$544. 
en la cultura dieciochesca alemana, no sin un largo esfuerzo intelectual, el hechizo cognoscitivo del sentido interno al que Baumgarten, sobre los rieles de la monadología leibniziana, concedió la legitimidad de ser el fondo inagotable del conocimiento verdadero, el cual pasaba de este modo a ser también el patrimonio cuasi natural del sujeto estético.

\section{Analogon rationis, el principio gnoseológico}

Baumgarten pudo mantener, no obstante, alejados de su fundamentación psicológica de la Estética los peligros irracionalistas del encumbramiento del sentido interno a los que la generación siguiente (Sulzer, Herder, Hamann...) sucumbiera, gracias al momento teodiceico que, junto al monadológico, también heredó de Leibniz y que puso el sello ilustrado de su pensamiento: la idea de la perfección del mundo. La originalidad de Baumgarten consistió en transferir esta idea al ámbito de la sensibilidad, ciertamente en los términos objetivos de perfectio phaenomenon, de belleza $^{47}$, pero también en los términos subjetivos de funcionamiento reglado de cada una de las facultades cognoscitivas del alma ${ }^{48} \mathrm{y}$, sobre todo, de unidad operativa de todas ellas en su diversidad bajo la dirección -como hemos visto- del sentido interno. Por tanto, junto a una perfección sensible de las cosas Baumgarten reconoció una perfección del sujeto sensible en su proceder representativo, a la que denominó analogon rationis. Si el sentido interno como (auto)conciencia psíquica es de por sí la forma de unidad subjetiva de la actividad representativa, el "análogo de la razón" designa el principio propiamente sintetizador y, por tanto, gnoseológico de dicha conscientia, mediante el cual ella lleva a cabo, al servicio de fines cognoscitivos, tanto una función integradora de las facultades del alma en un todo subjetivo cognoscente como una labor paralela de conexión y/o captación de la conexión de las representaciones mismas o contenidos representados según un orden determinado y cognoscible. Veamos brevemente esta correlación de funciones.

Baumgarten introduce la idea de la sensibilidad como "análogo de la razón" en su Metaphysica, §640, sirviéndose de un claro paralelismo con el proceder racional del intellectus, el cual en su curso reflexivo dirige la

47 En otro lugar he mostrado que la Estética de Baumgarten depende no sólo de la monadología sino también y especialmente de la Teodicea, una deuda teórica que no ha sido suficientemente destacada (v. M. Hernández Marcos, "Leibniz y el retorno de la sensibilidad en Baumgarten y Meier”, en prensa).

48 Téngase en cuenta que, según Baumgarten, las facultades inferiores de conocer no proceden, por así decir, arbitraria y caprichosamente; al contrario, la actividad representativa de cada una está regida por una ley propia (ley de la sensación, ley de la asociación, ley de las similitudes y diferencias de las cosas, etc.) 
atención hacia el todo de lo representado para aprehender nítidamente (distincte) su nexo vinculante, es decir, la ratio que conecta en un conjunto perceptivo unitario las diversas notas o percepciones (parciales) entre sí. Como en esta operación cognoscitiva entran en juego conjuntamente todas las facultades intelectuales superiores (perspicacia, memoria, juicio, presagio y hasta la facultad de expresión), todas ellas merecen el nombre genérico de "razón"49. Lo mismo cabe decir -arguye Baumgarten- del proceder conjunto de las diversas facultades representativas inferiores (sentidos, imaginación, memoria, perspicacia, capacidad de ficción, gusto, previsión y facultad de expresión) en el conocimiento sensible del mundo. Por eso "todas ellas, en cuanto que son similares a la razón en la representación del nexo de las cosas, constituyen el análogo de la razón, es decir, el conjunto [complexus] de las facultades del alma que representan confusamente ese nexo" $"$.

En la noción de analogon rationis hay, pues, dos aspectos fundamentales conectados entre sí. Por un lado, se halla la dimensión cognoscitivo-objetiva de la actualización o representación de un nexo o secuencia ordenada de fenómenos dentro de la conexión universal de las cosas. Lo peculiar de este modo de representación o cognitio sensitiva, a diferencia de la cognitio intellectualis, reside en que ese nexo del mundo es captado de manera "confusa", es decir, en su complejidad real, como conexión concreta de singularidades. La sensibilidad, como "análogo de la razón", es capaz, pues, de descubrir en la pluralidad rica e individual de los fenómenos del mundo una racionalidad que no es simple y formal ("simbólica", Baumgarten dixit), como la lógico-silogística de la razón, sino compleja y material, o sea, "intuitiva" y, en rigor, (subjetivo-)estética, ya que se trata únicamente de la belleza.

Mas, por otro lado, la captación o representación de esa conexión bella de las cosas singulares requiere un trabajo de integración del funcionamiento particular de cada una de las facultades psíquicas sensibles en un todo operativo común, capaz de detectar semejantes nexos estéticos. En virtud de esta dimensión subjetivo-cognoscitiva, el "análogo de la razón" se predica del conjunto de las facultades inferiores que intervienen coordinadamente en el trabajo del conocimiento sensible. Ahora bien,

${ }^{49}$ Cf. Metaphysica, §641. No podemos hacer aquí la historia conceptual del analogon rationis ni examinarlo más detenidamente. Remitimos a U. Franke, Kunst als Erkenntnis, pp. 51 ss.; y F. Solms, o.c., pp. 42-51, 108 ss. Sobre la deuda de este concepto con la tradición escolástica en Wolff v. Stefanie Buchenau, "Sinnlichkeit als Erkenntnisvermögen. Zum Begriff des Vernunftähnlichen in der Psychologie Christian Wolff", en: O.-P. Rudolph / J.-F. Goubet (Hg.), Die Psychologie Christian Wolffs, o.c., pp. 191-206.

50

Metaphysica, $\$ 640$, p. 38. 
como la labor cognoscitiva consiste fundamentalmente en la identificación de un nexo integrador de una diversidad de notas o percepciones parciales en una totalidad unitaria, compete -bajo la dirección de la conscientia intima- primordialmente la tarea del analogon rationis, por un lado, a esa fuerza de composición o combinación de imágenes en un todo que no tiene una réplica representativa correspondiente en el entendimiento, a saber, la capacidad de ficción (facultas fingendi, Dichtungsvermögen $)^{51}$, facultad creativa por excelencia; $y$, por otro lado, a la capacidad de apreciar o juzgar ese todo conexo de representaciones sensibles, con la que Baumgarten identifica la nueva noción estética de "gusto", la facultad de la crítica por antonomasia $^{52}$. Y la ley o principio conforme al cual opera el analogon rationis en la representación de la totalidad del universo desde la perspectiva de un nexo sensible integrador de cosas singulares, no es otro que el orden psicológico-subjetivo del tiempo (no el lógico-intelectual del raciocinio), sobre el cual se articula la asociación compleja de sensaciones presentes con imágenes pasadas y futuras similares en una unidad estético-argumentativa total.

Por último, el analogon rationis, como principio "legislador" $\mathrm{u}$ órgano subjetivo del conocimiento estético, constituye la base de la auténtica Tópica natural de la invención artística, la fuente psicológica de reglas para la creación de belleza. Esto es lo que de manera clara y contundente se dice en el $\S 140$ del Curso de Estética a modo de comentario sintético de la propuesta de una Tópica psicológica de la invención hecha en el parágrafo correspondiente de la Aesthetica. La idea, allí formulada, de resolver la Tópica estética particular en una apelación al catálogo de facultades cognoscitivas inferiores del alma para extraer de su funcionamiento reglado ("perfecto") los criterios de la creación artística equivale, en el texto del Curso, al simple trabajo de "representarse la razón que conoce el nexo de las cosas de manera confusa, pero vívida"53.

Se comprende ahora por qué la Estética, que como ciencia del conocimiento sensible pretende ser una nueva Tópica "particular", una doctrina del conjunto de criterios y reglas para la producción artística, es caracterizada también como ars analogi rationis. E igualmente se comprende que la invocación del sujeto propiamente estético, del artista de talento innato, como Tópica natural alternativa en el $\$ 140$ de la Aesthetica sea perfectamente coherente con la reivindicación simultánea de la Psicología empírica y su catálogo de facultades inferiores del alma. Pues ese sujeto estético natural -en rigor, el "espíritu bello"- no es más

${ }^{51}$ Cf. Metaphysica, $\$ 590$ ( $\$ 586$ ss.); Ästhetik, §34; Kollegium, §34, p. 89.

${ }^{52}$ Cf. Metaphysica, §§607-608; Ästhetik, §35; Kollegium, §35, p. 89.

${ }^{53}$ Kollegium, $\$ 140$, p. 140. 
que la figura personificada, el "ideal" concreto de aquella facultas cognoscitiva inferior del alma humana en su funcionamiento perfecto (mejorado con el entendimiento y la razón), ya que de él se exige no sólo una proporción adecuada de todas las capacidades sensibles de conocer, sino también una dotación de ellas en alto grado. Por eso Baumgarten hace hincapié en que el espíritu bello disponga de una dotación cualificada de las dos facultades principales en el proceso del conocimiento sensible: el "sentido interno", que ha de ser "especialmente fuerte" y "agudo", y la "facultad de ficción", que como portavoz del analogon rationis, es lo que define a un "esprit créateur" 54 . Esa labor conjunta de ambas facultades del alma operativamente unificadoras, la psicológico-formal y la gnoseológico-material, bajo la supervisión de la razón, queda nítidamente recogida en el $\$ 39$ de la Aesthetica, que resume por así decir el proceder innato unitario del espíritu bello:

El espíritu bello está dispuesto de tal modo que, abstrayendo no sólo de su estado pretérito -al que la memoria suele volver- sino también de sus propias sensaciones externas, centra su atención, en fin, en algún estado ficticio como si fuera futuro y lo intuye con perspicacia como bueno o malo, hasta ponerlo ante los ojos con los signos adecuados, y ello ciertamente bajo el gobierno del entendimiento y la razón. ${ }^{55}$

\section{Observaciones críticas a modo de conclusión}

Quisiera concluir con dos observaciones críticas, que pretenden cuestionar o al menos indicar las limitaciones del planteamiento de una Tópica natural en Baumgarten.

La primera se refiere a la aplicación misma de esa idea. ¿Ha elaborado Baumgarten su Estética realmente como una Tópica natural, propiamente psicológica? En la Aesthetica, no desde luego. En esta obra se ha limitado a proponer la figura "ideal" del "espíritu bello" en la Sección II de la obra y, más en general, la del sujeto estético completo (felix aestheticus) añadiendo a este respecto las cuatro secciones siguientes, y a señalar las disposiciones psíquicas que de manera proporcionada entre sí y en un grado superior de intensidad ha de poseer por naturaleza un alma creadora. Pero de ahí no se desprende ninguna enseñanza concreta acerca de qué reglas se han de observar en el uso de cada facultad psíquica ni

${ }^{54}$ Kollegium, $\$ 29$, p. 86, y $\$ 34$, p. 89 respectivamente.

${ }^{55}$ Ästhetik, §39. Baumgarten concede, de cara al perfeccionamiento, un papel supervisor y complementario a la razón y al entendimiento en el espíritu bello y en el proceso creativo (cf. Ästhetik, §38). 
cuál ha de ser la índole propia de las representaciones de cada una de ellas que ha de tenerse en cuenta en el momento de la creación artística. Baumgarten nos proporciona ahí el modelo del artista, pero nos deja sin el arte que podría aprenderse a partir del conocimiento psicológico de su naturaleza. En su lugar, construye la Aesthetica como una Tópica "objetiva", basada en los criterios de perfección del conocimiento sensible.

No obstante, hay que añadir que esa Tópica natural y "subjetiva" de la invención precedió a la Tópica objetiva y "artificial" de la Aesthetica en la trayectoria intelectual de Baumgarten: fue desarrollada en su escrito juvenil titulado Meditatione philosophicae de nonnullis ad poema pertinentibus (1735). En él ya se asume la Psicología empírica como fundamento de la nueva ciencia estética que allí por primera vez se plantea, y se fijan las reglas de la invención bella a partir de la tipología de las representaciones sensibles o "ideas", y de los principios y características propias de cada facultad psíquica correspondiente ${ }^{56}$. Pero hay en aquel texto inicial una limitación doble: por un lado, es un ensayo exclusivamente poetológico, orientado al arte de la invención literaria, y, por otro lado, no sigue aún el catálogo de facultades inferiores, más refinado y completo, que Baumgarten elaborará posteriormente en el capítulo psicológico de su Metaphysica (1739), sino en el más reducido e insuficiente, aunque esencial, que le proporcionaba la Psychologia empirica (1732) de Ch. Wolff: sensus ("afectos" incluidos, pero sin una noción válida de "sentido interno"), facultas imaginationis y facultas fingendi, además de la memoria. Ahora bien, una vez elaborada su propia Psicología empírica de orientación propiamente estética -como hemos visto-, ¿por qué no construyó su Aesthetica definitiva como una Tópica psicológica? Parece que el descubrimiento, también por la misma época (17391740), de los seis criterios de perfección de todo conocimiento y de su plausibilidad como criterios del conocimiento estético, cautivó tanto a Baumgarten que lo llegó a considerar su hallazgo más original, hasta el punto de que decidió por eso estructurar la parte "Heuristica" de su obra magna conforme a ellos.

La segunda y última observación tiene que ver con la utilidad efectiva o no de una Tópica natural (y, en general, de toda Tópica) para la creación artística. El $\S 141$ de la Aesthetica, con el que se cierra precisamente la sección dedicada a la Tópica, marca otra inflexión en el pensamiento estético de Baumgarten, puesto que allí se afirma que resulta superflua o estéril "cualquier clase de tópicos" cuando "irrumpe el ímpetu" y suenan "los céfiros propicios", ya que en ese estado de inspiración o

${ }^{56}$ Cf. Meditatione, §CXV. La parte de la "inventio", la más amplia, la conforman los $\S \S X I I-L X V$. 
"entusiasmo" hay que dejarse "arrastrar" por el viento que nos conduce directamente a la obra bella, sin prestar atención a si se cumplen las reglas del arte o si se están poniendo en juego todas las disposiciones naturales ${ }^{57}$. Aunque Baumgarten insiste en el control disciplinado del entusiasmo, y lo presenta como un requisito más del sujeto estético ideal, la concepción del ímpetu como un complementum facultatis ad actum, esto es, como el momento de activación de las disposiciones naturales del espíritu bello por el que se realiza o hace efectiva en una obra de arte la mera posibilidad innata contenida en él, indica que sin ese estado especial de exaltación no hay genuina creación artística o ésta se convierte en un acto fallido, por mucho talento innato y preparación de que disponga un sujeto estético. Mas con esta valoración del entusiasmo como estado excepcional y causa suficiente (verdadera "fuerza viva") de la producción bella Baumgarten sacaba a relucir además los poderes ocultos e inconscientes del espíritu humano, ya que esa activación extraordinaria de las facultades inferiores de conocer característica del impetus era el efecto particular del "fondo oscuro del alma", que de este modo salía repentinamente a la luz y se mezclaba por un momento con el reino de la claridad sensible ${ }^{58}$. El doble supuesto teodiceico y monadológico acerca del orden más perfecto posible del universo y de su presencia potencial en el alma humana permitía ciertamente a Baumgarten pensar que esa irrupción de las fuerzas oscuras en el sujeto estético contribuía de veras a la representación de belleza, de claridad y orden sensibles, en vez de a la producción de lo caótico y monstruoso. La generación alemana inmediatamente posterior al profesor de Frankfurt am Oder, la cual ya no participaba del optimismo teodiceico leibniziano, aunque sí del componente psicológico-irracional de la monadología, sólo tenía que extraer las consecuencias radicales de la doctrina del impetus aestheticus de Baumgarten para defender no sólo una teoría pre-romántica del genio sino también una estética de lo oscuro, lo impulsivo o lo desviado ${ }^{59}$, que obviamente era, por definición, a-tópica o u-tópica.

${ }^{57}$ Cf. Ästhetik, §141. De manera similar se concluye en Kollegium, §140, p. 140.

${ }^{58}$ Sobre el ímpetu o entusiasmo v. Ästhetik, Sec. V, espec. \$\$78-80; Kollegium, $\$ \$ 78-80$, pp. 113-116. Sobre la noción de "complementum facultatis ad actum", v. Metaphysica, $\$ 220$.

${ }^{59}$ V. Hans Adler, "Fundus Animae - der Grund der Seele. Zur Gnoseologie des Dunklen in der Aufklärung", Deutsche Vierteljahrsschrift für Literaturwissenschaft und Geistesgeschichte, 62:2 (1988), pp. 197-220, espec. 208 ss. 


\section{RESUMEN}

El objetivo de este artículo es examinar la propuesta de Baumgarten (Aesthetica, §140) de tomar el catálogo de las facultades sensibles del alma humana como Tópica [Topics] de la producción artística. Ello equivale ciertamente a convertir el sujeto estético y el talento natural del artista en criterios de la belleza y del arte, sin que ello signifique, no obstante, la reducción de estos últimos a la mera subjetividad expresiva del sentimiento y de la emoción. Al contrario, Baumgarten sigue pensando que el arte y la belleza están sujetos a reglas, sólo que esas reglas se basan en la naturaleza psíquica del hombre y en el peculiar funcionamiento de sus capacidades cognoscitivas. Tal es la convicción que alienta en su idea de una Tópica natural de la creación artística, fundada en la "Psicología empírica de los modernos". En este aspecto, el artículo pone de manifiesto, por un lado, que la elaboración filosófica de esa idea presupone el encumbramiento histórico del sentido interno como auténtica morada del arte y, a la vez, como fuente cognoscitiva suprema del hombre gracias a su concepción en términos de analogon rationis. Mas, por otro lado, el artículo muestra que Baumgarten no desarrolló, sin embargo, esa Tópica psicológica de la invención en su Aesthetica de 1750-58, sino en su primer escrito, de carácter poetológico: las Meditationes de nonnullis ad poema pertinentibus (1735).

Palabras clave: Tópica, Baumgarten, psicología empírica, sentido interno, analogon rationis

\section{ABSTRACT \\ THE INTERNAL SENSE, NATURAL TOPICS OF INVENTION IN A.G. BAUMGARTEN}

The purpose of this article is to examine Baumgarten's proposal-Aesthetica $\S 140$; analyzing the catalogue of the sensitive faculties of the human mind as well as the Topics of artistic production. Certainly, this would be equivalent to the conversion of the aesthetic subject and the artist natural talent into beauty and art criteria. This does not imply, however, reducing the latter to mere expressive subjectivity of feeling and emotion. Contrary, Baumgarten is still thinking that art and beauty are subject to rules; only those rules are based on the human psyche nature and, the rather peculiar function of her own cognitive abilities. Such conviction encourages his idea of an artistic creation founded up on Natural Topics; which is based on the "Empiric Psychology of the Moderns". This article considers the presumption that the philosophical elaboration of that idea implies an historical rising of internal sense; both, as an authentic art's abode and, as a supreme cognitive resource thanks to his conception in terms of "analogon rationis". On the other hand, this article shows that Baumgarten did not develop the Psychological Topics of invention on his Aesthetica (1750-58); rather he developed the Psychological Topics from his first poetological writing Meditationes de nonnullis ad poema pertinentibus (1735).

Keywords: Topics, Baumgarten, Empiric Psychology, internal sense, analogon rationis 